\title{
The influence of improved glycaemic control with insulin and sulphonylureas on acute phase and endothelial markers in Type II Diabetic subjects
}

\author{
J.S. Yudkin ${ }^{1}$, A.Panahloo ${ }^{1}$, C.Stehouwer ${ }^{2}$, J.J.Emeis ${ }^{3}$, K. Bulmer ${ }^{1}$, V.Mohamed-Ali ${ }^{1}$, A.E.Denver ${ }^{1}$ \\ ${ }^{1}$ Department of Medicine, University College London Medical School, Whittington Hospital, London, UK \\ ${ }^{2}$ Department of Medicine, Academic Hospital Vrije University Amsterdam, Netherlands \\ ${ }^{3}$ Gaubius Laboratory, Netherlands Organisation for Applied Scientific Research-Prevention and Health (TNO-PG), Leiden, \\ Netherlands
}

\section{Abstract}

Aims/hypothesis. Improved glycaemic control might reduce both microvascular and macrovascular complications of Type II diabetes (non-insulin-dependent) mellitus. To explore such possible mechanisms, we investigated the effects of intensive treatment on markers of endothelial dysfunction and of acute phase activation, using both sulphonylureas and insulin.

Methods. In a randomised cross-over study we gave sulphonylureas or insulin each for a period of 16 weeks to 22 poorly controlled Type II diabetic subjects who were being treated by diet. There was a 4 week washout period between each treatment. Subjects were studied at baseline and at the end of each treatment.

Results. Treatment with sulphonylureas and insulin resulted in similar improvements in glycaemic control (glycated haemoglobin, baseline: 11.8 [(SD 2.2)\%; after sulphonylureas: $8.6(1.2) \%, p<0.001$; after insulin: $8.6(1.2) \%, p<0.001]$ and in insulin sensitivity \{metabolic clearance rate of glucose, baseline: median 1.75 [interquartile (IQ) range 1.41, 2.27] $\mathrm{ml} \cdot \mathrm{kg}^{-1} \cdot \mathrm{min}^{-1}$; after sulphonylureas: $2.41(1.82$, $3.01) \mathrm{ml} \cdot \mathrm{kg}^{-1} \cdot \mathrm{min}^{-1}, p=0.001$; after insulin: 2.23 $\left.(1.92,2.75) \mathrm{ml} \cdot \mathrm{kg}^{-1} \cdot \mathrm{min}^{-1}, p=0.027\right\}$. There were no significant changes in concentrations of endothe- lial markers von Willebrand factor, cellular fibronectin, thrombomodulin, tissue plasminogen activator, soluble E-selectin or soluble intercellular adhesion molecule- 1 or in urinary albumin excretion rate after either treatment period. Concentrations of C-reactive protein were not significantly influenced by sulphonylureas but fell after insulin [baseline: median 4.50 (IQ range $1.37,6.44) \mu \mathrm{g} \cdot \mathrm{ml}^{-1}$; sulphonylureas: $2.69(0.88,9.65) \mu \mathrm{g} \cdot \mathrm{ml}^{-1}(p=0.53)$; insulin: 2.07 $\left.(1.16,5.24) \mu \mathrm{g} \cdot \mathrm{ml}^{-1}(p=0.017)\right]$. There were, however, no significant effects of either treatment on circulating concentrations of fibrinogen $(p=0.28-0.34)$ or of the proinflammatory cytokines interleukin- 6 or tumour necrosis factor- $\alpha(p=0.65-0.79)$.

Conclusion/interpretation. Markers of endothelial dysfunction and concentrations of proinflammatory cytokines in Type II diabetes are not influenced by improved glycaemic control over 16 weeks. Improved metabolic control with insulin could, however, be associated with reduced concentrations of the acute phase marker C-reactive protein. [Diabetologia (2000) 43: 1099-1106]

Keywords Glycaemic control, insulin, sulphonylureas, insulin resistance, endothelial dysfunction, tumour necrosis factor- $\alpha$, interleukin- 6 , C-reactive protein.
Received: 11 May 2000 and in revised form: 19 June 2000

Corresponding author: J.S. Yudkin, Department of Medicine, University College London Medical School, Clerkenwell Building, Archway Wing, Whittington Hospital, Archway Road, London N19 3UA, UK
Abbreviations: CHD, Coronary heart disease; CRP, C-reactive protein; AGE, advanced glycation end products; SSPG, steady state plasma glucose; MCR, metabolic clearance rate; sE-sel, Soluble E-selectin; sICAM-1, soluble intercellular adhesion molecule; tPA, tissue plasminogen activator; vWF, von Willebrand factor; AER, albumin excetion rate. 
Improved glycaemic control in Type I (insulin-dependent) diabetes mellitus has been shown to reduce the incidence of microvascular complications [1]. The UK Prospective Diabetes Study has recently shown statistically significantly lower risks of microvascular disease with intensified glycaemic control [2]. The mechanism of the relation between glycaemia and both microvascular and macrovascular disease is controversial. Microalbuminuria in patients with Type I diabetes and also those with Type II (non-insulin-dependent) diabetes mellitus clusters with a pronounced predisposition to severe microvascular (proliferative retinopathy) and macrovascular [coronary heart disease (CHD)] complications and it has been postulated that endothelial dysfunction underlies these associations $[3,4]$.

Insulin resistance has been linked to cardiovascular risk in diabetic and non-diabetic subjects $[5,6]$. Insulin resistance in itself clusters with microalbuminuria and with other markers of endothelial dysfunction [7]. We have recently suggested that these associations are the consequence of the common antecedence of adipose tissue-derived proinflammatory cytokines [8]. These molecules are expressed and released by adipocytes and endothelial cells as well as by inflammatory cells [9-11], and have important roles in insulin signalling [12] and in endothelial activation [13]. In addition, the circulating cytokine interleukin-6 (IL-6) is the major determinant of hepatic production of the acute phase proteins C-reactive protein (CRP) and fibrinogen [14]. There is growing evidence that increased concentrations of CRP predict the incidence of CHD over as long as 15 years [15-17] and it has been proposed that CRP itself has some role in the atherothrombotic process $[18,19]$. Circulating concetrations of the cytokines IL-6 and tumour necrosis factor- $\alpha(\mathrm{TNF}-\alpha)$ are increased in diabetic patients [20,21], perhaps as a consequence of the effects of advanced glycation end-products (AGE) on the expression of these cytokines by endothelial cells and macrophages [22,23]. Moreover, hyperglycaemia could have direct effects on endothelial function, either through mechanisms associated with 'pseudohypoxia' [24] or activation of protein kinase $\mathrm{C}$ [25] or through receptor-mediated activation by AGE [26].

We used stored blood samples from a cross-over study investigating the effects of improved glycaemic control on fibrinolysis, using sulphonylureas and insulin for 16 weeks each, in 22 poorly controlled Type II diabetic patients to assess the influences of reducing glycaemia on markers of endothelial activation, on hepatic acute phase proteins and on insulin sensitivity. We have previously shown that these two modes of therapy have different effects on fibrinolytic activity [27] which we believe results from divergent effects on endogenous production of insulin precursor molecules. Thus the study design also enabled us to compare the effects of these two different modes of therapy on endothelial and acute phase variables. The hypotheses we wished to test were that:

1. Improved glycaemic control, using either insulin or sulphonylureas, is associated with reduced concentrations of circulating markers of endothelial dysfunction.

2. Improved glycaemic control, using either insulin or sulphonylureas, is associated with reduced concentrations of acute phase markers and of cytokines.

3. Improvements in insulin action consequent upon improved glycaemic control are related to reduced endothelial and acute phase activation.

\section{Subjects and methods}

Subjects. Poorly controlled Type II diabetic patients $(n=22)$ referred to the outpatient department of the Whittington Hospital were recruited for a cross-over study to investigate the effects of different modes of glycaemic control on fibrinolytic activity [27]. In this study we used frozen samples from subjects investigated with the earlier protocol and whose characteristics are shown in Table 1. Diabetes was diagnosed using World Health Organisation (WHO) criteria [28]. The subjects were on diet alone and were investigated before the instigation of additional treatment. Patients with a history of ischaemic heart disease, renal or hepatic disease were excluded, as well as those on any other medication including antihypertensive agents and aspirin. The study was approved by the Islington Health Authority Ethical Committee and all subjects gave informed consent.

Study design. The study design has been described previously [27]. Briefly subjects were treated with insulin [premixed human soluble and isophane 30:70, (Humulin M3, Lilly, Indianapolis, Ind., USA)] or sulphonylurea (glibenclamide) once or twice daily each for 16 weeks in a randomised cross-over design, with a washout period of 4 weeks. Although this period of washout is inadequate to allow glycated haemoglobin values to return to baseline, it was not felt justifiable to withdraw drug treatment for longer in these poorly controlled patients. Dosage adjustment was made by telephone twice weekly on the basis of home blood glucose monitoring and weekly (first 4 weeks) followed by monthly visits, aiming for a fasting plasma glucose concentration of $6.0 \mathrm{mmol} / \mathrm{l}$ or less. The mean doses were $27.3 \pm 11.7$ units a day for insulin and $8.8 \pm 5.6$ milligrams a day for glibenclamide. Subjects were seen at baseline, after 16 weeks of treatment 1 , after a 4 week washout period and after 16 weeks of treatment 2 , having been told to omit their treatment on the evening before and the morning of study.

Subjects attended the Department of Medicine after an overnight fast. Weight, height, waist-to-hip ratio and skinfold measurements were done as described previously [27] and after a 10 -min rest blood pressure was recorded in duplicate with a random zero sphygmomanometer (Hawksley, Lancing, Sussex). Fasting venous blood samples were taken without venous stasis for measurement of concentrations of plasma glucose (fluoride), fructosamine, insulin, endothelial and hepatic acute phase markers, proinflammatory cytokines (lithium heparin), fibrinogen (acid citrate dextrose) and values of glycated 
Table 1. Characteristics of subjects, glycaemia and insulin sensitivity at baseline and after interventions

\begin{tabular}{|c|c|c|c|c|}
\hline & Baseline & After sulphonylurea & After insulin & $\begin{array}{l}p \text { (sulphonylurea } \\
\text { vs insulin) }\end{array}$ \\
\hline$\overline{\text { Age }}$ & $56.3(8.0)$ & & & \\
\hline Sex (female, male) & $8 \mathrm{f}, 14 \mathrm{~m}$ & & & \\
\hline Duration (years) & $4.0 \pm 6.2$ & & & \\
\hline BMI $\left(\mathrm{kg} / \mathrm{m}^{2}\right)$ & $28.9 \pm 3.8$ & $30.5 \pm 4.2^{\mathrm{c}}$ & $30.9 \pm 4.2(n=20)^{\mathrm{c}}$ & 0.31 \\
\hline Waist: hip ratio & $0.98 \pm 0.11$ & $0.93 \pm 0.08^{\mathrm{a}}$ & $0.93 \pm 0.09(n=20)^{\mathrm{a}}$ & 0.92 \\
\hline Fasting plasma glucose (mmol/l) & $12.7 \pm 3.0(n=21)$ & $9.3 \pm 2.2(n=21)^{\mathrm{c}}$ & $9.9 \pm 1.9(n=19)^{\mathrm{b}}$ & 0.16 \\
\hline Glycated haemoglobin (\%) & $11.8 \pm 2.2$ & $8.6 \pm 1.2^{\mathrm{c}}$ & $8.6 \pm 1.2(n=20)^{\mathrm{b}}$ & 0.63 \\
\hline Fructosamine $(\mu \mathrm{mol} / \mathrm{l})$ & $2.53 \pm 0.67$ & $1.96 \pm 0.46^{\mathrm{c}}$ & $1.98 \pm 0.31(n=19)^{\mathrm{c}}$ & 0.77 \\
\hline $\begin{array}{l}\text { Metabolic clearance rate of glucose } \\
\left(\mathrm{ml} \cdot \mathrm{kg} \cdot \mathrm{min}^{-1}\right)\end{array}$ & $\begin{array}{l}1.75(1.41-2.27) \\
(n=20)\end{array}$ & $2.41(1.82-3.01)^{\mathrm{c}}$ & $2.23(1.92-2.75)(n=19)^{\mathrm{a}}$ & 0.56 \\
\hline
\end{tabular}

Data are shown as means \pm SD or as median (range) for skewed data. The number $(n)$ of subjects is 22 except where indicated otherwise. Significance of differences were analysed using paired Student's $t$-tests on untransformed or logarithmi-

haemoglobin (EDTA). Blood was centrifuged at $3000 \mathrm{~g}$ for $10 \mathrm{~min}$ at $4{ }^{\circ} \mathrm{C}$ and stored immediately at $-70^{\circ} \mathrm{C}$.

An insulin sensitivity test was done using the modified Harano technique [29] as described previously [27]. This comprises a continuous infusion of insulin $\left[50 \mathrm{mU} \cdot \mathrm{kg}^{-1} \cdot \mathrm{h}^{-1}\right.$ Actrapid (Novo Nordisk, Basingstoke, UK)] and glucose $\left(6 \mathrm{mg} \cdot \mathrm{kg}^{-1}\right.$. $\mathrm{min}^{-1}$ ) for $150 \mathrm{~min}$, with arterialised blood being drawn from the contralateral arm every $5 \mathrm{~min}$ from 120 to $150 \mathrm{~min}$ for calculation of steady state plasma glucose concentration (SSPG). Metabolic clearance rate of glucose (MCR-glucose) was calculated as

MCR-glucose $=($ glucose infusion rate $/ \mathrm{SSPG})\left(\mathrm{ml} \cdot \mathrm{kg}^{-1}\right.$. $\left.\min ^{-1}\right)$.

Biochemical methods. Plasma glucose was measured using a glucose oxidase method (Glucose II analyser, Beckman, Brea, Calif., USA). Fructosamine was measured using a commercial kit (Roche Diagnostics, Hatfield, UK) with a Cobas Fara centrifugal analyser (intra-assay $\mathrm{CV}<3 \%$, normal range $1.55-2.10 \mu \mathrm{mol} / \mathrm{l}$ ) and haemoglobin $\mathrm{A}_{1 \mathrm{C}}$ by electroendosmosis (Corning, Palo Alto, Calif., USA) (normal range 6.5-8.5\%). Insulin was assayed using a specific in-house 2-site immunoenzymometric assay [30] and fibrinogen using the von Claus method (BCL, Lewes, Sussex). Plasma concentrations of thrombomodulin, von Willebrand factor, cellular fibronectin [31], soluble E-selectin (sE-sel), soluble intercellular adhesion molecule-1 (sICAM-1), tissue plasminogen activator (tPA) antigen and $\mathrm{C}$-reactive protein (CRP) were measured at the Gaubius Laboratory, TNO-PG, Leiden, Netherlands. Thrombomodulin was assayed using an ELISA kit (Diagnostica Stago, Asniéres, France) [32], von Willebrand factor (vWF) antigen by an ELISA essentially as described [33] using polyclonal antibodies from Dako (Glostrup, Denmark) and cellular fibronectin using a sandwich ELISA with a monoclonal antibody IST-9 (Sera-Lab, Crawley Down, UK) against the ED-A domain for capture and a peroxidase-conjugated polyclonal fibronectin antibody (Dako) for detection. Soluble E-selectin was measured with the Biotrak h-sELAM-1 ELISA kit (Amersham Life Science, Little Chalfont, UK) and sICAM-1 with a BioSource Europe (Nivelles, Belgium) ELISA kit. Tissue plasminogen activator antigen was measured by ELISA (Organon cally transformed data. Significance of differences after sulphonylurea or insulin compared with baseline are shown in the corresponding column.

${ }^{\mathrm{a}} p<0.05^{\mathrm{b}} p<0.01^{\mathrm{c}} p<0.001$

Teknika, Turnhout, Belgium) which recognise both the free form of the factor and complexes of tPA with plasminogen activator inhibitor-1. The C-reactive protein was measured with a highly sensitive ELISA procedure [34], that has a range of $0.25-10.25 \mu \mathrm{g} / \mathrm{ml}$ and an inter-assay CV of $8 \%$. Tumour necrosis factor- $\alpha$ and IL- 6 were measured by enzyme-linked immunosorbent assays (ELISA) (R and D Systems, Oxford, UK). Each subject collected three separate timed-overnight urine samples in the week before the study and albumin concentration was measured by an in-house adaptation of a previously described immunoassay $[27,35]$. Mean albumin excretion rate (AER) was expressed as $\mu \mathrm{g} \cdot \min$.

Statistical methods. The data were analysed with the Statistical Package for the Social Sciences (SPSS-PC) and are expressed as mean SD for normally distributed variables and median [interquartile (IQ) range] for skewed variables. As reported previously [27], concentrations of plasma glucose, fructosamine and haemoglobin $\mathrm{A}_{1 \mathrm{C}}$ values increased during the 4-week washout phase but did not return to baseline values between treatments. For this reason, as in our previous analyses, the variables after improved glycaemic control with either sylphylureas or insulin were compared with the pretreatment baseline, the validity of this approach being confirmed by a lack of treatment order effect. The data were analysed by paired Student's $t$-tests for normally distributed data (before or after logarithmic transformation) or by Wilcoxon's ranksum test for those data which remained skewed after logarithmic transformation (AER). Pearson or Spearman's rank correlation was used to explore the relations between changes in the variables. Statistical significance was taken as a $p$ value of less than 0.05 . We estimated that the number of subjects studied provided $80 \%$ power to detect, at the $5 \%$ level, a treatment difference of $11 \%$ in vWF and fibrinogen, of $13 \%$ in tissue plasminogen activator, of $20 \%$ in AER, of $38 \%$ in CRP, of $15 \%$ in IL-6, and of $9 \%$ in TNF- $\alpha$. The same power existed to detect treatment differences of between $11 \%$ and $17 \%$ in other variables. 
Table 2. Markers of endothelial function at baseline and after interventions

\begin{tabular}{|c|c|c|c|c|}
\hline & Baseline & After sulphonylurea & After insulin & $\begin{array}{l}p \text { (sulphonylu- } \\
\text { rea vs insulin) }\end{array}$ \\
\hline von Willebrand factor (\%) & $142(116-209)$ & $136(108-183)$ & $140(110-205)$ & 0.77 \\
\hline Cellular fibronectin (\%) & $304 \pm 162$ & $308 \pm 184$ & $311 \pm 191$ & 0.89 \\
\hline Thrombomodulin (ng/ml) & $126 \pm 71$ & $119 \pm 67$ & $125 \pm 64$ & 0.13 \\
\hline $\begin{array}{l}\text { Tissue plasminogen activator } \\
\text { antigen }(\mathrm{ng} / \mathrm{ml})\end{array}$ & $25.0 \pm 8.5$ & $26.5 \pm 6.9$ & $27.9 \pm 6.9$ & 0.46 \\
\hline $\begin{array}{l}\text { Soluble intercellular adhesion } \\
\text { molecule }^{-1}(\mathrm{ng} / \mathrm{ml})\end{array}$ & $498.6(445.2-698.9)$ & $545.7(423.9-730.2)(n=16)$ & $580.2(484.8-671.6)$ & 0.60 \\
\hline Albumin excretion rate $(\mu \mathrm{g} / \mathrm{min})$ & $7.9(5.9-22.4)(n=20)$ & $6.9(5.0-24.0)(n=20)$ & $6.8(4.0-14.6)$ & 0.76 \\
\hline
\end{tabular}

Data are shown as means \pm SD or as median (range) for skewed data. The number $(n)$ of subjects is 17 except whose indicated otherwise. Significance of differences were analysed using paired Student's $t$ tests on untransformed or logarithmically transformed data, except for albumin excretion rate, which remained skewed after transformation, where Wilcoxon's test was used. Significance of differences after sulphonylurea or insulin compared with baseline are shown in the corresponding column

Table 3. Acute phase proteins and proinflammatory cytokines at baseline and after interventions

\begin{tabular}{lllll}
\hline & Baseline & After sulphonylurea & After insulin & $p$ (sulphonylurea vs insulin) \\
\hline Fibrinogen $(\mathrm{mg} / \mathrm{dl})$ & $251 \pm 46(n=22)$ & $239 \pm 30(n=22)$ & $243 \pm 47(n=19)$ & 0.67 \\
C-Reactive protein $(\mu \mathrm{g} / \mathrm{ml})$ & $4.50(1.37-6.44)$ & $2.69(0.88-9.65)$ & $2.07(1.16-5.24)^{\mathrm{a}}$ & 0.12 \\
Interleukin-6 $(\mathrm{pg} / \mathrm{ml})$ & $2.30(1.55-5.35)$ & $1.80(1.37-4.19)$ & $1.85(1.42-4.30)$ & 0.82 \\
Tumour necrosis factor- $\alpha(\mathrm{pg} / \mathrm{ml})$ & $3.00(2.57-4.20)$ & $3.21(2.64-4.50)$ & $3.06(2.58-4.60)$ & 0.83 \\
\hline
\end{tabular}

Data are shown as means \pm SD or as median (range) for skewed data. The number $(n)$ of subjects is 17 except where indicated otherwise. Significance of differences were analysed using paired Student's $t$ tests on untransformed or logarithmi-

\section{Results}

We studied 22 subjects (14 men and 8 women) at baseline and after 16 weeks of treatment with sulphonylureas and 20 completed both limbs of the study. One subject declined insulin therapy and one developed renal calculi during the insulin phase. Analyses of all the variables presented showed no evidence of effects of treatment order. Both treatments resulted in an statistically significant increase in body mass index, treatment with insulin, but not with sulphonylureas, resulted in a statistically significant increase in subscapular-to-triceps ratio, implying truncal fat deposition. The treatments produced parallel falls in glycaemia as indicated by the concentrations of fasting plasma glucose, fructosamine and glycated haemoglobin values, and parallel increases in serum insulin concentration. Values of glycated haemoglobin and concentrations of fructosamine were reduced to close to and within the normal range respectively, although fasting plasma glucose concentrations were marginally increased because treatment omitted before the study protocol. As reported previously [27], both treatments produced an increase in MCR-glucose, which was not statistically significantly different between the two treatments. cally transformed data. Significance of differences after sulphonylurea or insulin compared with baseline are shown in the corresponding column.

${ }^{\mathrm{a}} p<0.05$

The effects of these interventions on concentrations of plasminogen activator inhibitor- 1 and of proinsulin-like molecules have also been reported previously [27].

We estimated seven markers of endothelial activation/dysfunction, six in plasma and AER (Table 2). For none of these variables was there a significant difference either between concentrations at baseline and after either treatment phase or after the two treatment periods.

Fibrinogen concentrations were not significantly influenced by sulphonylurea or insulin treatment (Table 3). Concentrtations of CRP were significantly lower after insulin treatment $(p=0.017)$ but not after sulphonylurea treatment $(p=0.53)$ (Fig. 1$)$. Concentrations of IL- 6 and TNF- $\alpha$ were not influenced by improved glycaemic control and were not different between treatments (Table 3).

We sought correlations between changes in the three measures of glycaemia and in those of insulin sensitivity, with changes in the endothelial and acute phase markers. Because we found no statistically significant between-treatment differences for any variable except CRP and in view of the the small numbers of subjects and the additional risk of spurious associations with increasing numbers of comparisons, 


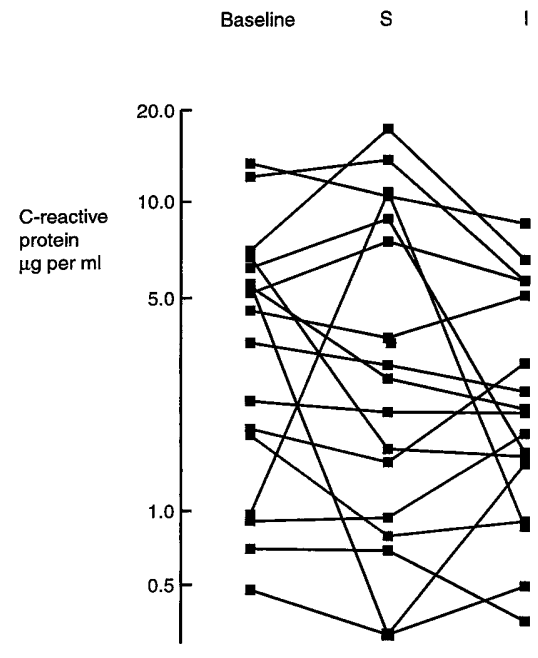

Fig. 1. Concentrations of C-reactive protein at baseline and after interventions

$\mathrm{S}=$ after sulphonylurea, $\mathrm{I}=$ after insulin, $* p=0.017$, $* * p=0.53, * * * p=0.12$

we combined the changes from baseline to the end of treatment on both interventions. Despite there being no significant effect of either treatment on concentrations of $\mathrm{vWF}$, changes in these concentrations with treatment correlated with each measure of change in glycaemia $(r=0.40-0.49)$. There were no other consistent correlations of changes in measures of glycaemia or insulin sensitivity with those in other endothelial or acute phase markers.

\section{Discussion}

We have investigated 22 subjects before and after 16 weeks of intensive treatment with a sulphonylurea and with insulin, which resulted in virtual normalisation of concentrations of fructosamine and glycated haemoglobin values with the assays used for this study. We found a parallel improvement in insulin sensitivity with both treatments. Neither treatment resulted, however, in any change in any of the circulating endothelial markers or in AER. Although there was no statistically significant effect on the concentrations of fibrinogen or the proinflammatory cytokines IL-6 and TNF- $\alpha$, those of CRP fell significantly with insulin but not with sulphonylurea treatment .

We used the seven measures shown in Table 2 as markers of endothelial activation. It is recognised that several of the circulating markers are synthesised by several cell types, and could thus lack specificity. Moreover, a number of endothelial markers respond to acute phase stimuli $[8,36,37]$ so that the delineation between endothelial marker and acute phase protein is not distinct. For this reason we have referred to

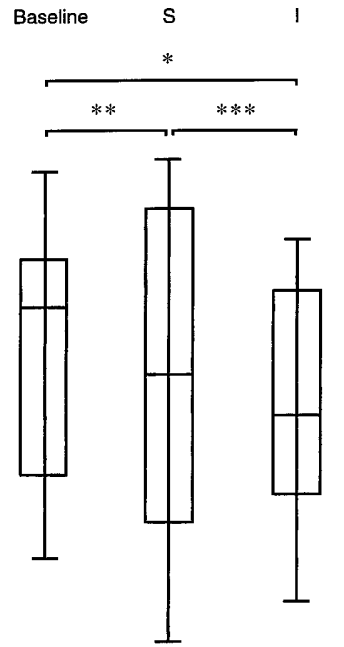

CRP and fibrinogen as 'hepatic acute phase proteins' [38].

Some studies have suggested hyperglycaemia influences a variety of markers of endothelial dysfunction, either directly mediated through glucose $[24,25,39-41]$ or through the influence of AGEs $[22,23,26,42,43]$ or Amadori-modified proteins [44]. There are few studies which have assessed the influence of improved glycaemic control on such markers. Changes in glycaemia have been associated with parallel alterations in endothelium-dependent vasodilatation [45-47] and reduced concentrations of endothelial markers [48], although a decrease in values of glycated haemoglobin is not universally associated with a decrease in vWF concentrations [49-51]. In our study, despite there being no significant change in concentrations of $\mathrm{vWF}$, there were positive associations between changes in each measure of glycaemia and those in vWF, although multiple comparisons increase the risks of Type I error. This might suggest that a potentially beneficial effect of improved glycaemic control is neutralised by adverse changes in vWF concentrations mediated by treatment-related mechanisms. We found no associations between changes in concentrations of sE-sel and the degree of glycaemia and insulin sensitivity, associations which have been described previously $[48,52]$. The lack of influence of improved glycaemic control on AER contrasts with previous reports in newly diagnosed [53,54] and established [55] diabetic patients.

There are few data on the influence of glycaemic control, treatment or insulin resistance on circulating concentrations of cytokines and hepatic acute phase proteins [56,57]. Both the oxidative stress associated with hyperglycaemia [58] and the influence of AGEs on endothelial cells and macrophages [22, 23] could link poor glycaemic control with increased expression and secretion of proinflammatory cytokines. Our finding of reductions in CRP concentrations with insulin but not with sulphonylurea treatment, unassociated with changes in concentrations of cytokines, 
could be a spurious finding consequent upon multiple comparisons. It does, however, raise the possibility of actions of insulin on hepatic expression of acute phase proteins. Insulin has been shown to be a powerful inhibitor of cytokine-induced transcription of acute phase proteins in rat hepatoma cells [59]. Our observation that changes in concentrations of CRP were not associated with changes in concentrations of cytokines might support such an interpretation. The smaller increase in insulin concentrations on sulphonylurea treatment did not produce a fall in concentrations of CRP $(p=0.53)$. We found no parallel changes in fibrinogen concentrations, possibly because fibrinogen concentrations in diabetes seems to be related to changes in half-life in diabetic patients [60], in contrast to those of CRP, which are virtually dependent on synthetic rate [61]. Insulin treatment could be associated with increases in fibrinogen concentrations $[62,63]$.

In non-diabetic subjects, we have found statistically significant relations between some markers of hepatic acute phase activation and several components of the insulin-resistance syndrome [8]. In this study, despite statistically significant improvements in insulin sensitivity, this was not accompanied by reductions in circulating concentrations of proinflammatory cytokines, which argues against a role for such molecules in the insulin resistance associated with hyperglycaemia.

Thus, in a crossover study, we have found no influence of improved glycaemic control on markers of endothelial dysfunction, although insulin treatment was associated with a fall in the concentration of CRP. These observations could imply that other approaches to improving endothelial function, such as treatment with angiotensin converting enzyme inhibitors or antioxidants, could have greater advantages than glycaemic control in the prevention of CHD in people with Type II diabetes.

Acknowledgements. The study was supported in part by a grant from Lilly Industries (A. Panahloo) and by Group Support from the British Diabetic Association. Aspects of this study were also supported by grants from the Wellcome Trust (12441/1.5) and British Heart Foundation (PG92133, PG97150). C. Stehouwer is supported by a fellowship from the Diabetes Fonds Netherland and the Netherlands Organisation for Scientific Research (NWO) and is also a member of the Institute of Cardiovascular Research at Vrije University, Amsterdam. J.J. Emeis is supported by Grant 28-2623 from the Praeventiefonds. We are also grateful to Diabetes and Related Diseases Research, the Joan Oliver Bequest and Sue Hammerson for financial support.

\section{References}

1. The Diabetes Control and Complications Trial Research Group (1993) The effect of intensive treatment of diabetes on the development and progression of long-term complications in insulin-dependent diabetes mellitus. $\mathbf{N}$ Engl $\mathbf{J}$ Med 329: 977-986

2. United Kingdom Prospective Diabetes Study (UKPDS) Group (1998) Intensive blood-glucose control with sulphonylureas or insulin compared with conventional treatment and risk of complications in patients with Type II diabetes (UKPDS 33). Lancet 352: 837-853

3. Stehouwer CDA, Lambert J, Donker AJM, van Hinsbergh VWM (1997) Endothelial dysfunction and pathogenesis of diabetic angiopathy. Cardiovasc Res 34: 55-68

4. Stehouwer CDA, Yudkin JS, Nosadini R, Fioretto P (1998) How heterogeneous is microalbuminuria in diabetes mellitus? The case for 'benign' and 'malignant' microalbuminuria. Nephrol Dial Transplant 13: 2751-2754

5. Martin FI, Stocks AE (1968) Insulin sensitivity and vascular disease in insulin-dependent diabetics. BMJ 2: 81-82

6. Reaven GM (1988) Role of insulin resistance in human disease. Diabetes 37: 1595-1607

7. Pinkney JH, Stehouwer CDA, Coppack SW, Yudkin JS (1997) Endothelial dysfunction: cause of the insulin resistance syndrome. Diabetes 46 [Suppl 2]: S9-S13

8. Yudkin JS, Stehouwer CDA, Emeis JJ, Coppack SW (1999) C-reactive protein in healthy subjects - associations with obesity, insulin resistance and endothelial dysfunction. A potential role for cytokines originating from adipose tissue? Arterioscler Thromb Vasc Biol 19: 972-978

9. Hotamisligil GS, Arner P, Caro JF, Atkinson RL, Spiegelman BM (1995) Increased adipose tissue expression of tumor necrosis factor- $\alpha$ in human obesity and insulin resistance. J Clin Invest 95: 2409-2415

10. Mohamed-Ali V, Goodrick S, Rawesh A et al. (1997) Human subcutaneous adipose tissue releases IL6 but not TNF- $\alpha$ in vivo. J Clin Endo Metab 82: 4196-4200

11. Podor TJ, Jirik FR, Loskutoff DJ, Carson DA, Lotz M (1989) Human endothelial cells produce IL-6. Lack of responses to exogenous IL-6. Ann NY Acad Sci 557: 374-385.

12. Hotamisligil GS, Peraldi P, Budavari A, Ellis R, White MF, Spiegelman BM (1996) IRS-1-mediated inhibition of insulin receptor tyrosine kinase activity in TNF- and obesity-induced insulin resistance. Science 271: 665-668

13. Romano M, Sironi M, Toniatti C et al. (1997) Role of IL-6 and its soluble receptor in induction of chemokines and leukocyte recruitment. Immunity 6: 1-20

14. Heinrich PC, Castell JV, Andus T (1990) Interleukin-6 and the acute phase response. Biochem J 265: 621-636

15. Ridker PM, Cushman M, Stampfer MJ, Tracy RP, Hennekens CH (1997) Inflammation, aspirin and the risk of cardiovascular disease in apparently healthy men. $\mathbf{N}$ Engl $\mathbf{J}$ Med 336: 973-979

16. Koenig W, Sund M, Frohlich M et al. (1999) C-reactive protein, a sensitive marker of inflammation, predicts future risk of coronary heart disease in initially healthy middleaged men: results from the MONICA (Monitoring Trends and Determinants in Cardiovascular Disease) Augsburg Cohort Study, 1984-1992. Circulation 99: 237-242

17. Kuller LH, Tracy RP, Shaten J, Meilahn EN for the MRFIT Research Group (1996) Relation of C-reactive protein and coronary heart disease in the MRFIT nested case-control study. Am J Epidemiol 144: 537-547

18. Lagrand WK, Visser CA, Hermans WT et al. (1999) C-reactive protein as a cardiovascular risk factor: more than an epiphenomenon? Circulation 100: 96-102 
19. Cermak J, Key NS, Bach RR, Balla J, Jacob HS, Vercellotti GM (1993) C-reactive protein induces human peripheral blood monocytes to synthesise tissue factor. Blood 82: 513-520

20. Pickup JC, Crook MA (1998) Is Type II diabetes mellitus a disease of the innate immune system? Diabetologia 41: 1241-1248

21. Katsuki A, Sumida Y, Murashima S et al. (1998) Serum levels of tumor necrosis factor-alpha are increased in obese patients with noninsulin-dependent diabetes mellitus. J Clin Endocrinol Metab 83: 859-862

22. Brownlee M (1994) Glycation and diabetic complications. Diabetes 43: 836-841

23. Schmidt AM, Hori O, Brett J, Yan SD, Wautier JL, Stern D (1994) Cellular receptors for advanced glycation end products. Implications for induction of oxidant stress and cellular dysfunction in the pathogenesis of vascular lesions. Arterioscler Thromb Vasc Biol 14: 1521-1528

24. Williamson JR, Chang K, Frangos M et al. (1993) Hyperglycemic pseudohypoxia and diabetic complications. Diabetes 42: 801-813

25. Ishii H, Jirousek MR, Koya D et al. (1996) Amelioration of vascular dysfunction in diabetic rats by an oral PKC inhibitor. Science 272: 728-731

26. Schmidt AM, Hasu M, Popov D et al. (1994) Receptor for advanced glycation end products (AGEs) has a central role in vessel wall interactions and gene activation in response to circulating AGE proteins. Proc Natl Acad Sci USA 91: 8807-8811

27. Panahloo A, Mohamed-Ali V, Andrés C, Denver AE, Yudkin JS (1998) Effect of insulin versus sulfonylurea therapy on cardiovascular risk factors and fibrinolysis in type II diabetes. Metabolism 47: 637-643

28. World Health Organisation Study Group on Diabetes Mellitus (1985) Technical report series No 727, WHO, Geneva

29. Heine RJ, Home PD, Poncher M et al. (1985) A comparison of 3 methods for assessing insulin sensitivity in subjects with normal and abnormal glucose tolerance. Diabetes Res 2: $113-120$

30. Mohamed-Ali V, Gould MM, Gillies S et al. (1995) Associations of proinsulin-like molecules with lipids and fibrinogen in non-diabetic subjects - evidence against a modulating role for insulin. Diabetologia 38: 1110-1116

31. Peters JH, Maunder RJ, Woolf AD, Cochrane CG, Ginsberg MH (1989) Elevated plasma levels of ED1 + ("cellular") fibronectin in patients with vascular injury. J Lab Clin Med 113: 586-597

32. Amiral J, Adam M, Mimilla F, Larrivaz I, Chambrette B, Boffa MC (1994) Design and validation of a new immunoassay for soluble forms of thrombomodulin and studies on plasma. Hybridoma 13: 205-213

33. Ingerslev J (1987) A sensitive ELISA for von Willebrand factor (vWF:Ag). Scand J Clin Lab Invest 47: 143-149

34. Myrup B, de Maat M, Rossing P, Gram J, Kluft C, Jespersen J (1996) Elevated fibrinogen and the relation to acute phase response in diabetic nephropathy. Thromb Res 81: 485-490

35. Chesham J, Anderton SW, Kingdom CFM (1986) Rapid competitive enzymoimmunoassay for albumin in urine. Clin Chem 32: 669-671

36. Pottinger BE, Read RC, Paleolog EM, Higgins PG, Pearson JD (1989) Von Willebrand factor is an acute phase reactant in man. Thromb Res 53: 387-394

37. Hunt BJ, Jurd KM (1998) Endothelial cell activation. A central pathophysiological process. $\mathrm{Br}$ Med J 316: $1328-1329$
38. Whicher J, Biasucci L, Rifai N (1999) Inflammation, the acute phase response and atherosclerosis. Clin Chem Lab Med 37: 495-503

39. Mordes DB, Lazarchick J, Colwell JA, Sens DA (1983) Elevated glucose concentrations increase factor VIIIR: AG levels in human umbilical vein endothelial cells. Diabetes 32: $876-878$

40. Baumgartner-Parzer SM, Wagner L, Pettermann M, Gessl A, Waldhäusl W (1995) Modulation by high glucose of adhesion molecule expression in cultured endothelial cells. Diabetologia 38: 1367-1370

41. Cominacini L, Fratta Pasini A, Garbin U et al. (1995) Elevated levels of soluble E-selectin in patients with IDDM and NIDDM : relation to metabolic control. Diabetologia 38: $1122-1124$

42. Schmidt AM, Hori O, Chen JX et al. (1995) Advanced glycation endproducts interacting with their endothelial receptor induce expression of vascular cell adhesion molecule-1 (VCAM-1) in cultured human endothelial cells and in mice. A potential mechanism for the accelerated vasculopathy of diabetes. J Clin Invest 96: 1395-1403

43. Smulders RA, Stehouwer CDA, Schalkwijk CG, Donker AJM, van Hinsbergh VWM, TeKoppele JM (1998) Distinct associations of $\mathrm{HbA}_{1 \mathrm{C}}$ and the urinary excretion of pentosidine, an advanced glycosylation end product, with markers of endothelial function in insulin-dependent diabetes mellitus. Thromb Haemost 80: 52-57

44. Schalkwijk CG, Ligtvoet N, Twaalfhoven H et al. (1999) Amadori albumin in type I diabetic patients: correlation with markers of endothelial function, association with diabetic nephropathy, and localisation in retinal capillaries. Diabetes 48: 2446-2453

45. Williams SB, Goldfine AB, Timimi FK et al. (1998) Acute hyperglycemia attenuates endothelium-dependent vasodilatation in humans in vivo. Circulation 97: 1695-1701

46. Jaap AJ, Pym CA, Seamark C, Shore AC, Tooke JE (1995) Microvascular function in Type II (non-insulin-dependent) diabetes: improved vasodilatation after one year of good glycaemic control. Diabet Med 12: 1086-1091

47. Vehkavaara S, Mäkimattila S, Schlenzka A, Vakkilainen J, Westerbacka J, Yki-Järvinen H (2000) Insulin therapy improves endothelial function in Type II diabetes. Arterioscler Thromb Vasc Biol 20: 545-550

48. Albertini JP, Valensi P, Lormeau B et al. (1998) Elevated concentrations of soluble E-selectin and vascular cell adhesion molecule-1 in NIDDM. Effect of intensive insulin treatment. Diabetes Care 21: 1008-1013

49. Stehouwer CDA, Stroes ESG, Hackeng WHL, Mulder PGH, den Ottolander GJH (1991) Von Willebrand Factor and development of diabetic nephropathy in IDDM. Diabetes 40: 971-976

50. Knobl P, Schernthaner G, Schnack C et al. (1994) Haemostatic abnormalities persist despite glycaemic improvement by insulin therapy in lean Type II diabetic patients. Thromb Haemost 71: 692-697

51. van der Knaap JH, de Boer AC, Pannebakker MA, van Heerde W, den Ottolander GJ (1985) The effect of diabetes regulation on platelet release, fibrinolysis and coagulation tests, before and after stimulation with DDAVP. Thromb Haemost 53: 118-121

52. Chen NG, Holmes M, Reaven GM (1999) Relationship between insulin resistance, soluble adhesion molecules, and mononuclear cell binding in healthy volunteers. J Clin Endocrinol Metab 84: 3485-3489

53. United Kingdom Prospective Diabetes Study (UKPDS) Group (1998) Relationships of urinary albumin and Nacetylglucosaminidase to glycaemia and hypertension at di- 
agnosis of Type II (non-insulin-dependent) diabetes mellitus and after 3 months diet therapy (UKPDS IX). Diabetologia 36: 835-842

54. Schmitz A, Hansen HH, Christensen T (1989) Kidney function in newly diagnosed Type II (non-insulin-dependent) diabetic patients, before and during treatment. Diabetologia 32: 434-439

55. Vasquez B, Flock EV, Savage PJ et al. (1984) Sustained reduction of proteinuria in Type II (non-insulin-dependent) diabetes following diet-induced reduction of hyperglycaemia. Diabetologia 26: 127-133

56. Desfaits AC, Serri O, Renier G (1998) Normalisation of plasma lipid peroxides, monocyte adhesion, and tumor necrosis factor-alpha production in NIDDM patients after gliclazide treatment. Diabetes Care 21: 487-493

57. Morohoshi M, Fujisawa K, Uchimura I, Numano F (1996) Glucose-dependent interleukin-6 and tumor necrosis factor production by human peripheral blood monocytes in vitro. Diabetes 45: 954-959
58. Baynes JW (1991) Role of oxidative stress in development of complications in diabetes. Diabetes 40: 405-412

59. Campos SP, Baumann H (1992) Insulin is a prominent modulator of the cytokine-stimulated expression of acutephase plasma protein genes. Mol Coll Biol 12: 1789-1797

60. Jones RL, Peterson C (1979) Reduced fibrinogen survival in diabetes mellitus. A reversible phenomenon. J Clin Invest 63: 485-493

61. Vigushin DM, Pepys MB, Hawkins PN (1993) Metabolic and scintigraphic studies of radioiodinated human C-reactive protein in health and disease. J Clin Invest 91: 1351-1357

62. Missov RM, Stolk RP, van der Bom JG et al. (1996) Plasma fibrinogen in NIDDM: the Rotterdam Study. Diabetes Care 19: 157-159

63. Emanuele N, Azad N, Abraira C et al. (1998) Effect of intensive glycemic control on fibrinogen, lipids, and lipoproteins. Veterans Affairs Cooperative Study in Type II Diabetes Mellitus. Arch Intern Med 158: 2485-2490 